\title{
Prognostic role of copeptin with all-cause mortality after heart failure: a systematic review and meta-analysis
}

This article was published in the following Dove Press journal:

Therapeutics and Clinical Risk Management

5 January 2017

Number of times this article has been viewed

\section{Peng Zhang \\ Xiaomei Wu \\ Guangxiao Li \\ Hao Sun \\ Jingpu Shi}

Department of Clinical Epidemiology, Center of Evidence-Based Medicine, Institute of Cardiovascular Disease, The First Hospital of China Medical University, Shenyang, People's Republic of China
Correspondence: Jingpu Shi

Department of Clinical Epidemiology, Center of Evidence-Based Medicine, Institute of Cardiovascular Disease, The First Hospital of China Medical University, No I55, North Nanjing Street, Shenyang I I000I, People's Republic of China Email sjp562013@I26.com
Background: As the C-terminal section of vasopressin precursor, copeptin has been recently suggested as a new prognostic biomarker after heart failure (HF). Thus, the aim of this study was to evaluate the prognostic value of plasma copeptin level with all-cause mortality in patients with HF.

Methods: Comprehensive strategies were used to search relevant studies from electronic databases. Pooled hazard ratios (HRs) and standardized mean differences (SMDs) together with their $95 \%$ confidence intervals (CIs) were calculated. Subgroup analysis and sensitivity analysis were performed to find the potential sources of heterogeneity.

Results: A total of 5,989 participants from 17 prospective studies were included in this metaanalysis. A significant association was observed between circulating copeptin levels and risk of all-cause mortality in patients with $\mathrm{HF}$ (categorical copeptin: $\mathrm{HR}=1.69,95 \% \mathrm{CI}=1.42-2.01$; per unit copeptin: $\mathrm{HR}=1.03,95 \% \mathrm{CI}=1.00-1.07$; log unit copeptin: $\mathrm{HR}=3.26,95 \% \mathrm{CI}=0.95-11.25$ ). Pooled SMD showed that copeptin levels were significantly higher in patients with HF who died during the follow-up period than in survivors ( $\mathrm{SMD}=1.19,95 \% \mathrm{CI}=0.81-1.57$ ). Subgroup analyses also confirmed this significant association, while sensitivity analyses indicated that the overall results were stable.

Conclusion: This study demonstrated that circulating copeptin seemed to be a novel biomarker to provide better prediction of all-cause mortality in patients with HF.

Keywords: heart failure, copeptin, all-cause mortality, meta-analysis

\section{Introduction}

As the terminal stage of all kinds of cardiovascular diseases, including hypertension, myocardial infarction (MI) and cardiomyopathy, heart failure (HF) is known as one of the leading burdens to the health care system not only for cost but also for morbidity and mortality all over the world. ${ }^{1}$ According to the estimation of the US Centers for Disease Control and Prevention, the total cost of treatment for HF was up to \$34 billion in $2010 .{ }^{2}$ Furthermore, mortality rates in patients with HF were even similar to the 5-year mortality rates of some most severe cancers, which were up to $50 \%{ }^{3}$

Copeptin, which was first discovered in 1972, is located in the C-terminal section of the arginine vasopressin (AVP) precursor (pro-AVP) and consists of 39 amino acid glycopeptides. ${ }^{4}$ Evidence demonstrated that copeptin is released from pro-AVP together and equivalent with AVP. AVP is widely known as a vital hormone with numerous effects in the human body, such as central nervous, hemodynamic, hemostatic and endocrinologic effects. ${ }^{5}$ Plasma AVP levels increase apparently during the process of some acute and chronic diseases, and the measurement of AVP would be useful 
for the diagnosis of patients. ${ }^{6}$ However, because of the pulse release mode and the short half-life of AVP, the clinical application of AVP is restricted. ${ }^{7}$ Recently, as a result of the long-term stability and being easy to measure, copeptin has been used as an alternative marker of AVP and suggested as a biomarker for poor clinical outcome and mortality of some diseases, such as pneumonia, ${ }^{8} \mathrm{MI},{ }^{9}$ diabetes, ${ }^{10,11} \mathrm{HF},{ }^{12}$ stroke $^{13}$ and transient ischemic attack. ${ }^{14,15}$

In the current study, we performed a systematic review and meta-analysis aimed to assess the prognostic value of circulating copeptin levels for all-cause mortality in patients with HF.

\section{Methods}

We used comprehensive electronic literature databases to search for potential studies that estimated the prognostic value of copeptin in patients with HF. The current study was conducted according to the Meta-analysis of Observational Studies in Epidemiology (MOOSE) checklist. ${ }^{16}$

Electronic literature databases (PubMed, the Web of Science, EMBASE, Cochrane Collaboration Databases, Medline, Chinese National Knowledge Infrastructure, Wan Fang Database and Chong Qing VIP Database) were searched for relevant studies published up to October 2016 without restrictions of the type of document and language. The following search terms were used: ("heart failure" OR "HF" OR "cardiac dysfunction") and ("copeptin" OR "C-terminal provasopressin” OR “CT-pro-AVP”). Moreover, we also searched the references of the selected articles and textbooks manually as a source of related studies.

Two reviewers (PZ and GL) selected the relevant articles according to the inclusion criteria independently. Studies included in this meta-analysis should satisfy the following criteria: 1) adult patients with HF; 2) prospective studies that estimated the association between copeptin and all-cause mortality risk in patients with $\mathrm{HF}$ and 3 ) studies that reported the description of risk estimation of the relative risks (RRs) or hazard ratios (HRs) together with their corresponding 95\% confidence intervals (CIs) or provided mean differences of copeptin in survivors and non-survivors. For studies on the same population or overlapping data, only the one with the largest number of subjects was included.

Information of all involved studies was carefully extracted by two reviewers (PZ and XW) independently, and any disagreement was settled by other reviewers (GL and HS). The following information was extracted from all the eligible studies: first author's name, publication year, country, number of centers, type of patients, follow-up period, sample size (including number of survivors and non-survivors), mean age, baseline copeptin levels, type of copeptin measurement, RRs or HRs together with their $95 \%$ CIs and mean copeptin levels with standard deviations (SDs); if not reported, median copeptin levels with interquartile ranges (IQRs) were used.

According to the Newcastle-Ottawa Quality Assessment Scale (NOS), ${ }^{17}$ two reviewers (PZ and HS) assessed the methodological quality of each eligible study independently. Disagreements were resolved from discussion with other reviewers (GL and $\mathrm{XW}$ ). The following three aspects were used to assess the quality of cohort studies: the selection of participants, the comparability of the exposed and unexposed cohort and the assessment of the outcome. The total scores of each study ranged between 0 and 9 , and studies achieving scores $>6$ were regarded as high quality.

According to the different reporting forms of copeptin, we separately performed three meta-analyses for the risk estimation between copeptin and all-cause mortality in patients with HF based on unit copeptin, logarithm of copeptin, and copeptin categories, respectively. For the studies that reported the categorical data, we used the RRs (or HRs) between highest and lowest categories of copeptin. When both multivariate and univariate results were available, the former was preferred in the current analysis. Furthermore, for the studies that reported RRs, the RRs were regarded as HRs directly, as pooled HRs were used for all the risk estimations.

Based on the strength of association between copeptin and all-cause mortality in patients with HF, pooled standardized mean differences (SMDs) were estimated according to the mean copeptin levels \pm SDs reported in the studies. For studies in which the mean copeptin levels \pm SDs were unavailable, medians were treated as mean values directly and IQRs were used to estimate the SDs using the following formula: $\mathrm{SD}=\mathrm{IQR} / 1.35 .^{18}$

$I^{2}$ test was used for testing the heterogeneity among different studies. ${ }^{19} I^{2}>50 \%$ was considered as a sign of high heterogeneity using random-effects model. Otherwise, the fixed-effects model was used. ${ }^{20}$ Subgroup analyses were performed to find the potential sources of heterogeneity, on the basis of sample size, age, female percentage, baseline copeptin, number of centers, type of HF (acute or chronic), measurement methods of copeptin, quality of studies and follow-up period.

Test for funnel plot asymmetry was conducted when at least 10 studies were included. Only six studies were included in our analyses for HR estimation by copeptin categories and unit copeptin, therefore the potential publication 
bias was not assessed. Sensitivity analysis was conducted by removing one study each time. $P<0.05$ was regarded as statistically significant, and all statistical analyses were performed using the STATA 12.0 (Stata, College Station, TX, USA).

\section{Results}

A detailed description of the process of study selection is shown in Figure 1. At first, 254 potential articles were identified from the databases searching, and only 161 articles remained after removing the duplicate studies. After assessing based on the title and abstract, 109 irrelevant studies were excluded. Finally, a total of 52 articles were fully reviewed, and 17 prospective studies providing data for 5,989 participants met the inclusion criteria and were included in the current meta-analysis.

The main characteristics of the included studies are listed in Table 1. The mean follow-up period ranged from 14 days to 13 years, while the sample size ranged from 40 to 1,237 . The detailed scores of included studies are listed in Table 2. A total of 14 studies reported RRs or HRs with $95 \%$ CIs for the risk estimation between baseline copeptin level and allcause mortality in patients with HF, 11 out of these 14 studies reported results from multivariate regression analyses and the other three studies reported results from univariate regression analyses only. As for the evaluation of the strength, three out of nine studies provided the mean copeptin levels with SDs, while the remaining six studies provided median copeptin levels with IQRs only.

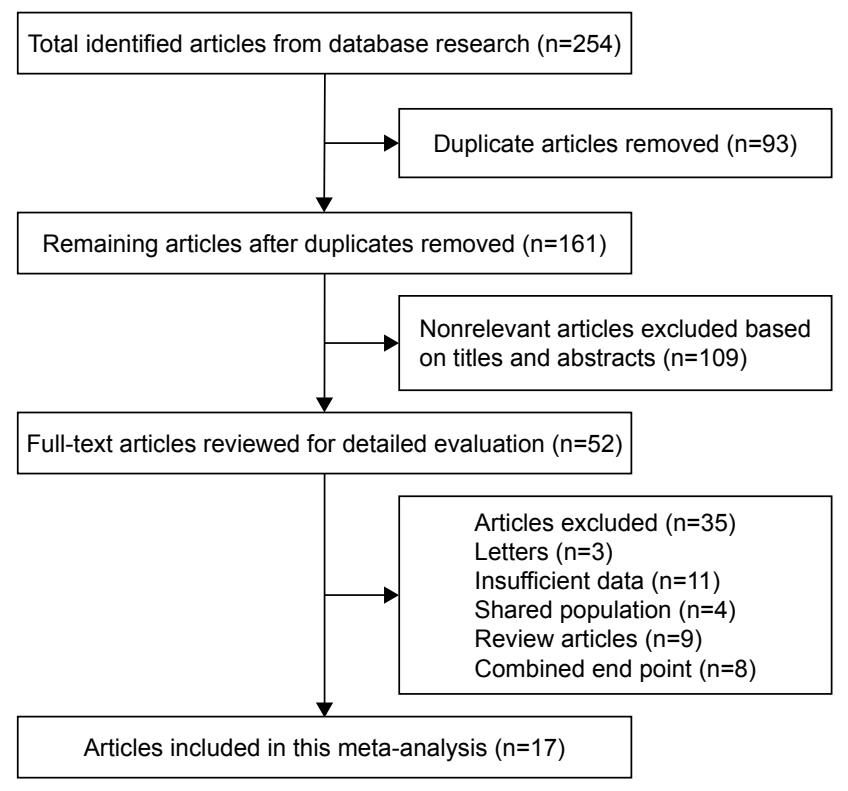

Figure I Flowchart of study selection and exclusion process.

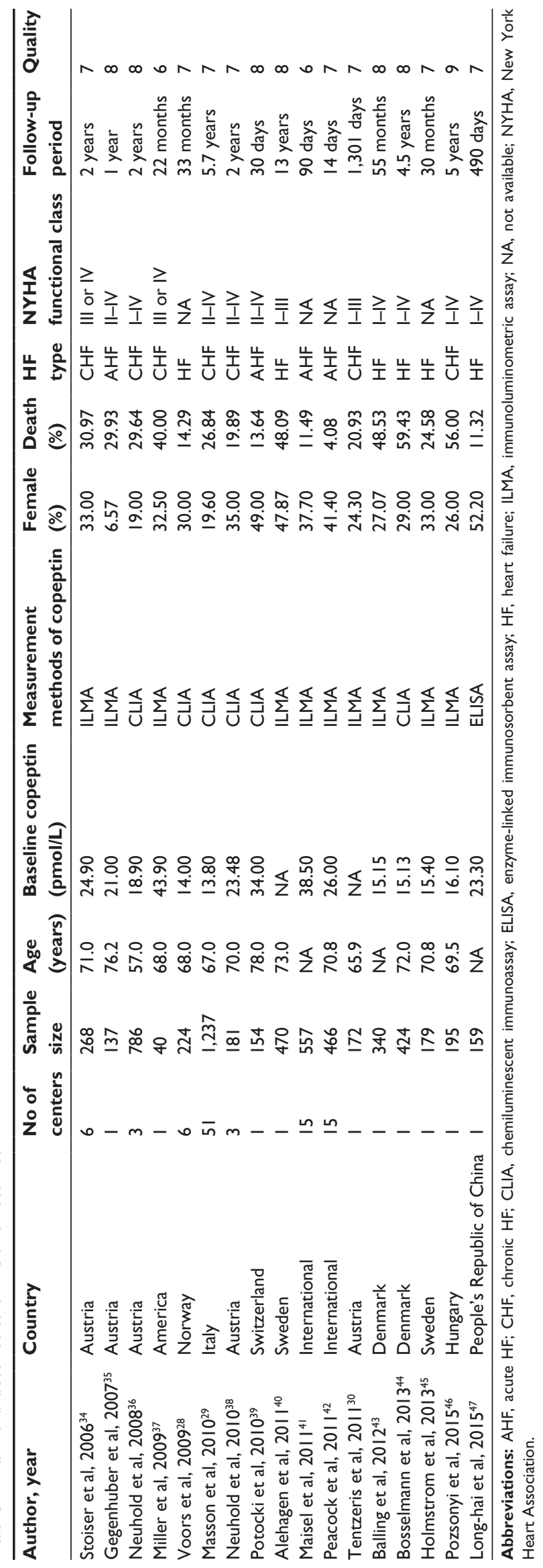


Table 2 The scores of included studies assessed by NOS

\begin{tabular}{|c|c|c|c|c|c|}
\hline Author & Year & Selection & Comparability & Outcome & Quality \\
\hline Stoiser et $\mathrm{al}^{34}$ & 2006 & $* * *$ & $*$ & $* * *$ & 7 \\
\hline Gegenhuber et $\mathrm{al}^{35}$ & 2007 & $* * *$ & $* *$ & $* * *$ & 8 \\
\hline Neuhold et $\mathrm{al}^{36}$ & 2008 & $* * * *$ & $*$ & $* * *$ & 8 \\
\hline Miller et $\mathrm{al}^{37}$ & 2009 & $* * *$ & $*$ & $* *$ & 6 \\
\hline Voors et $\mathrm{al}^{28}$ & 2009 & $* * *$ & $* *$ & $* *$ & 7 \\
\hline Masson et $\mathrm{al}^{29}$ & 2010 & $* * *$ & $* *$ & $* *$ & 7 \\
\hline Neuhold et al ${ }^{38}$ & 2010 & $* * *$ & $*$ & $* * *$ & 7 \\
\hline Potocki et $\mathrm{al}^{39}$ & 2010 & $* * *$ & $* *$ & $* * *$ & 8 \\
\hline Alehagen et $\mathrm{al}^{40}$ & 2011 & $* * *$ & $* *$ & $* * *$ & 8 \\
\hline Maisel et $\mathrm{al}^{41}$ & 2011 & $* * *$ & $*$ & $* *$ & 6 \\
\hline Peacock et $\mathrm{al}^{42}$ & 2011 & $* * *$ & $*$ & $* * *$ & 7 \\
\hline Tentzeris et $\mathrm{a}^{30}$ & 2011 & $* * *$ & $*$ & $* * *$ & 7 \\
\hline Balling et $\mathrm{al}^{43}$ & 2012 & $* * * *$ & $*$ & $* * *$ & 8 \\
\hline Bosselmann et $\mathrm{al}^{44}$ & 2013 & $* * *$ & $* *$ & $* * *$ & 8 \\
\hline Holmstrom et $\mathrm{al}^{45}$ & 2013 & $* * *$ & $*$ & $* * *$ & 7 \\
\hline Pozsonyi et a ${ }^{46}$ & 2015 & $* * * *$ & $* *$ & $* * *$ & 9 \\
\hline Long-hai et al ${ }^{47}$ & 2015 & $* * * *$ & $*$ & $* *$ & 7 \\
\hline
\end{tabular}

Note: *, **, *** and $* * * *$ means I point, 2 points, 3 points and 4 points, respectively.

Abbreviation: NOS, Newcastle-Ottawa Quality Assessment Scale.

Six studies including 2,913 patients with HF reported the risk estimation according to copeptin categories. No evidence of heterogeneity was observed $\left(I^{2}=45.4 \%, P=0.103\right)$, and the fixed-effects model was used in this meta-analysis. The pooled HR was 1.69 (95\% CI $=1.42-2.01$; Figure 2). Table 3 shows the detailed information of subgroup analyses by copeptin categories, and the significant association between copeptin and all-cause mortality in patients with HF was also confirmed in each subgroup.

Six studies reported the RRs or HRs with $95 \%$ CIs for the risk estimation of all-cause mortality in patients with $\mathrm{HF}$ by unit copeptin. A total of 1,769 participants were included

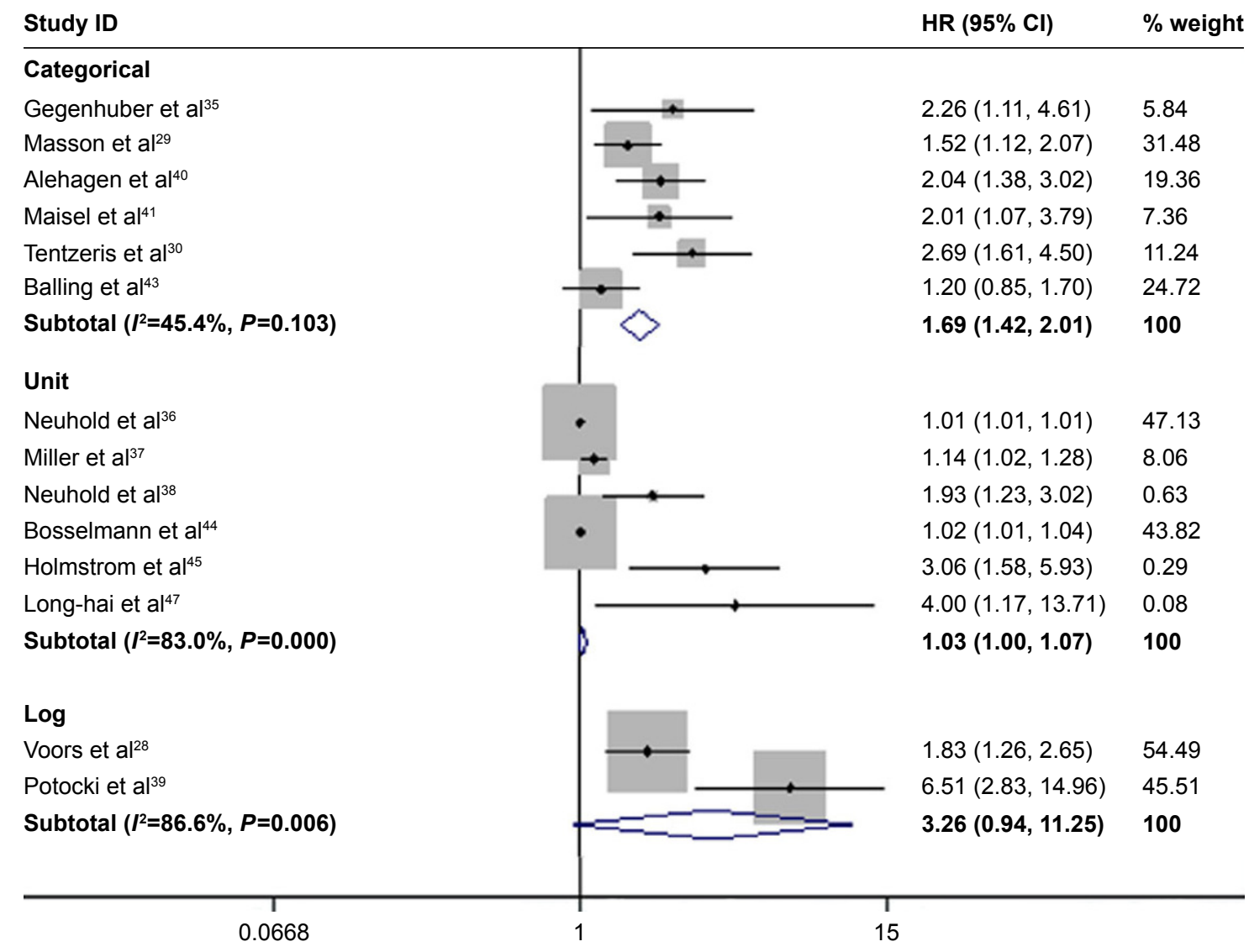

Figure 2 Pooled estimate of HR of all-cause mortality with copeptin in patients with HF. Abbreviations: $\mathrm{Cl}$, confidence interval; $\mathrm{HF}$, heart failure; $\mathrm{HR}$, hazard ratio. 
Table 3 Pooled HRs of all-cause mortality by copeptin levels in subgroup analyses

\begin{tabular}{|c|c|c|c|c|c|c|c|c|c|c|}
\hline & \multicolumn{5}{|c|}{ Categorical copeptin } & \multicolumn{5}{|c|}{ Per unit copeptin } \\
\hline & $\mathbf{N}$ & HR $(95 \% \mathrm{Cl})$ & $P$-value & $I^{2}(\%)$ & $P_{\mathrm{h}}$-value & $\mathbf{N}$ & HR $(95 \% \mathrm{Cl})$ & $P$-value & $I^{2}(\%)$ & $P_{\mathrm{h}}$-value \\
\hline Overall & 6 & $1.69(1.42-2.01)$ & 0.000 & 45.4 & 0.103 & 6 & $1.03(1.00-1.07)$ & 0.074 & 83.0 & 0.000 \\
\hline \multicolumn{11}{|l|}{ Sample size } \\
\hline$<200$ & 2 & $2.53(1.67-3.85)$ & 0.000 & 0.0 & 0.698 & 4 & $1.97(1.12-3.47)$ & 0.018 & 81.7 & 0.001 \\
\hline$\geq 200$ & 4 & $1.56(1.29-1.88)$ & 0.000 & 35.4 & 0.200 & 2 & $1.01(1.00-1.02)$ & 0.003 & 38.6 & 0.202 \\
\hline \multicolumn{11}{|l|}{ Age (years) } \\
\hline$<70$ & 2 & $1.77(1.36-2.30)$ & 0.000 & 71.4 & 0.062 & 2 & $1.06(0.94-1.19)$ & 0.337 & 76.7 & 0.038 \\
\hline$\geq 70$ & 2 & $2.09(1.48-2.94)$ & 0.000 & 0.0 & 0.805 & 3 & I.7I (0.88-3.32) & 0.111 & 89.1 & 0.000 \\
\hline \multicolumn{11}{|c|}{ Percentage of females } \\
\hline$<30 \%$ & 4 & $1.58(1.29-1.93)$ & 0.000 & 60.4 & 0.056 & 2 & $1.01(1.00-1.02)$ & 0.003 & 38.6 & 0.202 \\
\hline$\geq 30 \%$ & 2 & $2.03(1.46-2.84)$ & 0.000 & 0.0 & 0.969 & 4 & $1.97(1.12-3.47)$ & 0.018 & 81.7 & 0.001 \\
\hline \multicolumn{11}{|c|}{ Baseline copeptin } \\
\hline$<20$ & 2 & $1.37(1.09-1.72)$ & 0.007 & 0.1 & 0.317 & 3 & $1.02(0.99-1.04)$ & 0.209 & 83.9 & 0.002 \\
\hline$\geq 20$ & 2 & $2.12(1.32-3.40)$ & 0.002 & 0.0 & 0.810 & 3 & $1.67(0.95-2.91)$ & 0.074 & 77.1 & 0.013 \\
\hline \multicolumn{11}{|l|}{ No of centers } \\
\hline I & 4 & $1.75(1.40-2.18)$ & 0.000 & 64.0 & 0.040 & 4 & I.23 (0.99-I.52) & 0.068 & 84.1 & 0.000 \\
\hline$>1$ & 2 & $1.60(1.22-2.11)$ & 0.001 & 0.0 & 0.437 & 2 & $1.34(0.72-2.52)$ & 0.361 & 87.6 & 0.005 \\
\hline \multicolumn{11}{|l|}{ Mortality } \\
\hline$<30 \%$ & 4 & I.84 (I.46-2.32) & 0.000 & 24.6 & 0.264 & 4 & $1.95(1.02-3.74)$ & 0.044 & 87.3 & 0.000 \\
\hline$\geq 30 \%$ & 2 & $1.52(1.17-1.96)$ & 0.002 & 74.7 & 0.047 & 2 & $1.06(0.96-1.18)$ & 0.260 & 71.9 & 0.059 \\
\hline \multicolumn{11}{|l|}{ HF type } \\
\hline AHF & 2 & $2.12(1.32-3.40)$ & 0.002 & 0.0 & 0.810 & 0 & - & - & - & - \\
\hline $\mathrm{CHF}$ & 2 & $1.77(1.36-2.30)$ & 0.000 & 71.4 & 0.062 & 3 & I.14 (0.96-I.36) & 0.134 & 83.8 & 0.002 \\
\hline \multicolumn{11}{|c|}{ Inclusion of NYHA class I } \\
\hline Yes & 3 & $1.70(1.35-2.15)$ & 0.000 & 74.3 & 0.020 & 3 & $1.01(1.00-1.03)$ & 0.101 & 68.9 & 0.040 \\
\hline No & 2 & $1.62(1.22-2.14)$ & 0.001 & 0.3 & 0.317 & 2 & $1.42(0.85-2.35)$ & 0.179 & 80.0 & 0.025 \\
\hline \multicolumn{11}{|c|}{ Measurement methods } \\
\hline ILMA & 5 & $1.78(1.44-2.19)$ & 0.000 & 52.9 & 0.075 & 2 & $1.77(0.68-4.62)$ & 0.246 & 87.9 & 0.004 \\
\hline CLIA & 1 & $1.52(1.12-2.07)$ & 0.008 & - & - & 3 & $1.02(0.99-1.04)$ & 0.153 & 79.3 & 0.008 \\
\hline \multicolumn{11}{|c|}{ Quality according to NOS } \\
\hline$>6$ & 5 & $1.67(1.39-2.00)$ & 0.000 & 54.8 & 0.065 & 5 & $1.02(0.99-1.06)$ & 0.202 & 84.1 & 0.000 \\
\hline \multicolumn{11}{|l|}{ Follow-up time } \\
\hline$\leq 2$ years & 2 & $2.12(1.32-3.40)$ & 0.002 & 0.0 & 0.810 & 4 & $1.20(0.98-1.46)$ & 0.076 & 82.5 & 0.001 \\
\hline$>2$ years & 4 & $1.63(1.36-1.97)$ & 0.000 & 63.0 & 0.044 & 2 & $1.68(0.57-4.90)$ & 0.344 & 90.5 & 0.001 \\
\hline \multicolumn{11}{|l|}{ Analysis } \\
\hline Univariate & 1 & $2.69(1.6 \mathrm{I}-4.50)$ & 0.000 & - & - & 3 & I.7I (0.88-3.34) & 0.117 & 89.4 & 0.000 \\
\hline Multivariate & 5 & $1.59(1.33-1.91)$ & 0.000 & 28.9 & 0.229 & 3 & $1.09(0.94-1.27)$ & 0.260 & 75.8 & 0.016 \\
\hline \multicolumn{11}{|c|}{ Adjusted for age } \\
\hline Yes & 3 & $1.52(1.24-1.85)$ & 0.000 & 49.4 & 0.138 & 3 & $1.64(0.86-3.14)$ & 0.136 & 84.0 & 0.002 \\
\hline No & 3 & $2.36(1.67-3.35)$ & 0.000 & 0.0 & 0.775 & 3 & $1.16(0.95-1.42)$ & 0.150 & 86.7 & 0.001 \\
\hline
\end{tabular}

Notes: $\mathrm{N}$, number of studies; $P, P$-value for $\mathrm{HR}=\mathrm{I} ; P_{\mathrm{h}}, P$-value for heterogeneity test.

Abbreviations: AHF, acute HF; CHF, chronic HF; $95 \% \mathrm{Cl}$, 95\% confidence interval; CLIA, chemiluminescent immunoassay; HF, heart failure; HR, hazard ratio; ILMA, immunoluminometric assay; NOS, Newcastle-Ottawa Quality Assessment Scale; NYHA, New York Heart Association.

in this meta-analysis, and a significant heterogeneity among studies was observed $\left(I^{2}=83.0 \%, P<0.001\right)$. Using the random-effects model, the pooled HR of all-cause mortality was 1.03 (95\% CI =1.00-1.07; Figure 2). As presented in Table 3, a few subgroups by unit copeptin corroborated this association between copeptin and all-cause mortality in patients with HF, even though other subgroups showed a borderline association, such as the higher mortality group $(\geq 30 \%)$ and the younger age group $(<70)$.

The other two studies reported the risk estimation by $\log$ copeptin, and the pooled HR was $3.26(95 \% \mathrm{CI}=0.95-11.25$;
Figure 2) using a random-effects model $\left(I^{2}=86.6 \%\right.$, $P<0.001)$. Subgroup analyses according to log copeptin were not conducted, as the number of original studies was relatively small.

Based on the pooled SMD, nine studies provided data for 630 deaths and 2,152 survivors were included in this meta-analysis. Obvious heterogeneity between studies was observed $\left(I^{2}=92.1 \%, P<0.001\right)$, and the random-effects model was chosen. The result of the pooled SMD (1.19, 95\% CI =0.81-1.57; Figure 3) showed that baseline copeptin levels were significantly higher in patients who died during 


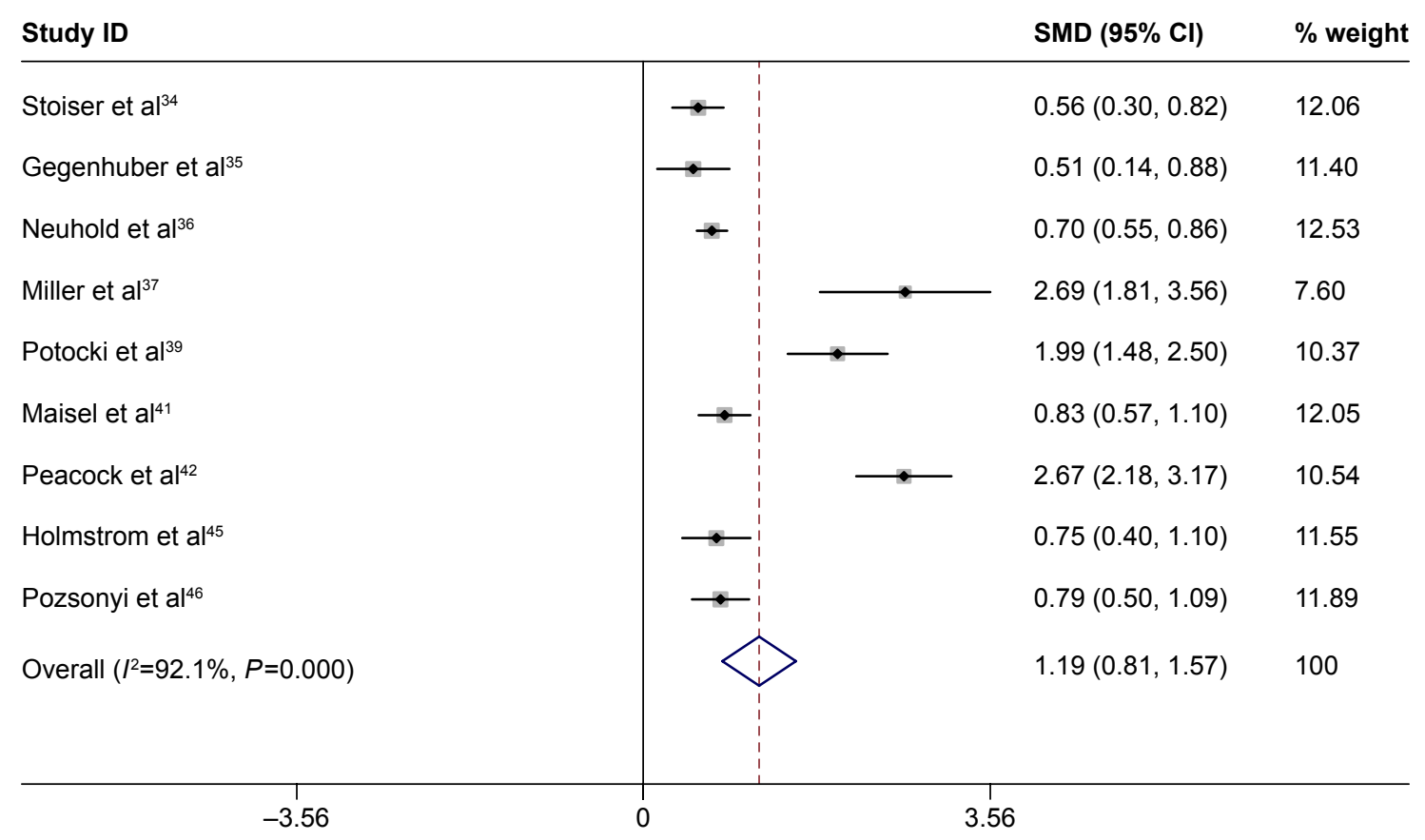

Figure 3 Pooled estimate of standardized mean copeptin value with all-cause mortality in patients with HF. Abbreviations: $\mathrm{Cl}$, confidence interval; $\mathrm{HF}$, heart failure; SMD, standardized mean difference.

the follow-up period than survivors, indicating that higher circulating copeptin levels were positively associated with the risk of all-cause mortality in patients with HF. The results of subgroup analyses are presented in Table 4 , and the significant association was also observed in each subgroup.

Sensitivity analyses were conducted by removing one study at a time to observe the influence of each included study on the overall pooled estimates. As shown in Figure 4, no single study was observed to significantly influence the overall pooled estimates, which indicated that our overall results were statistically stable.

\section{Discussion}

AVP, also called antidiuretic hormone, was produced by the hypothalamus and secreted from the neurohypophysis in reaction to osmotic and hemodynamic stimuli. ${ }^{21}$ When released into the blood flow, AVP began to take different peripheral effects through three different receptors, namely $V_{1 a}, V_{1 b}$, and $\mathrm{V}_{2}$, respectively. In patients with $\mathrm{HF}$, increased AVP contributed to the process of left ventricular dysfunction, by activating $\mathrm{V}_{1 \mathrm{a}}$ and $\mathrm{V}_{2}$ receptors and making further effects such as leading to water retention, peripheral vasoconstriction, and myocardial remodeling. ${ }^{22}$ Generally, plasma AVP level increased sharply in patients with HF and was relevant to the severity of disease. ${ }^{23}$ Thus, knowledge of circulating AVP levels would be of vital importance to the diagnosis and assessment of therapeutic intervention with HF. However, due to the shortages of the half-time of 24 minutes, unstability in frozen plasma and difficult measurement method, the clinical use of AVP for HF was restricted. ${ }^{24,25}$

Copeptin, also named the AVP-associated glycopeptides, was derived from pro-AVP together with AVP, neurophysin II and a signal peptide. ${ }^{26}$ Different from AVP, copeptin was discovered to be stable even at room temperature and easily measured by sandwich immunoassay, with results stable in 20-60 minutes..$^{27}$ In recent years, despite the exact mechanism connecting copeptin with the severity of HF not clear, the clinical use of copeptin as a surrogate marker of AVP was proposed. Early studies had indicated that a higher circulating copeptin level was an independent prognostic factor not only for mortality but also for poor functional outcome in patients with HF. ${ }^{28,29}$ These multiple studies in different clinical settings showed that circulating copeptin levels were necessary for risk stratification in patients with HF. ${ }^{30,31}$

A previous research conducted by Sun et $\mathrm{al}^{32}$ suggested that copeptin was a prognostic biomarker for all-cause mortality in patients with cardio-cerebrovascular disease. However, comprehensive study about the prognostic role of copeptin in patients with HF was not reported. To our best knowledge, this was the first systematic review and meta-analysis attempting to evaluate the prognostic value of copeptin and all-cause mortality in patients with HF. Through this collaborative meta-analysis, our study provided new and powerful evidence to the suggestion of using copeptin as an 
Table 4 Pooled SMDs in subgroup analyses

\begin{tabular}{|c|c|c|c|c|c|}
\hline & $\mathbf{N}$ & SMD $(95 \% \mathrm{Cl})$ & $P$-value & $I^{2}(\%)$ & $P_{h}$-value \\
\hline Overall & 9 & $1.19(0.81-1.57)$ & 0.000 & 92.1 & 0.000 \\
\hline \multicolumn{6}{|l|}{ Sample size } \\
\hline$<200$ & 5 & $1.25(0.67-1.84)$ & 0.000 & 95.1 & 0.000 \\
\hline$\geq 200$ & 4 & $1.15(0.56-1.73)$ & 0.000 & 89.7 & 0.000 \\
\hline \multicolumn{6}{|l|}{ Age (years) } \\
\hline$<70$ & 3 & I.I7 (0.58-I.78) & 0.000 & 89.6 & 0.000 \\
\hline$\geq 70$ & 5 & $1.28(0.53-2.02)$ & 0.001 & 94.9 & 0.000 \\
\hline \multicolumn{6}{|c|}{ Percentage of female } \\
\hline$<30 \%$ & 3 & $0.70(0.57-0.83)$ & 0.000 & 0.0 & 0.502 \\
\hline$\geq 30 \%$ & 6 & $1.52(0.87-2.18)$ & 0.000 & 94.3 & 0.000 \\
\hline \multicolumn{6}{|l|}{ No of centers } \\
\hline 1 & 5 & $1.25(0.67-1.84)$ & 0.000 & 95.1 & 0.000 \\
\hline$>1$ & 4 & $1.15(0.56-1.73)$ & 0.000 & 89.7 & 0.000 \\
\hline \multicolumn{6}{|l|}{ Mortality } \\
\hline$<30 \%$ & 6 & $1.21(0.70-1.72)$ & 0.001 & 93.7 & 0.000 \\
\hline$\geq 30 \%$ & 3 & $1.18(0.46-1.89)$ & 0.000 & 90.4 & 0.000 \\
\hline \multicolumn{6}{|l|}{ HF type } \\
\hline AHF & 4 & $1.49(0.58-2.39)$ & 0.001 & 95.3 & 0.000 \\
\hline $\mathrm{CHF}$ & 4 & $0.94(0.54-1.33)$ & 0.000 & 85.8 & 0.000 \\
\hline \multicolumn{6}{|c|}{ Inclusion of NYHA class I } \\
\hline Yes & 2 & $0.72(0.59-0.86)$ & 0.000 & 0.0 & 0.602 \\
\hline No & 4 & $1.36(0.53-2.19)$ & 0.001 & 93.2 & 0.000 \\
\hline \multicolumn{6}{|c|}{ Measurement methods } \\
\hline ILMA & 7 & $1.18(0.69-1.66)$ & 0.000 & 92.3 & 0.000 \\
\hline CLIA & 2 & $1.32(0.06-2.59)$ & 0.040 & 95.5 & 0.000 \\
\hline \multicolumn{6}{|c|}{ Quality according to NOS } \\
\hline$>6$ & 7 & $1.10(0.67-1.53)$ & 0.000 & 92.8 & 0.000 \\
\hline \multicolumn{6}{|c|}{ Follow-up time } \\
\hline$\leq 2$ years & 7 & $1.34(0.84-1.84)$ & 0.000 & 94.0 & 0.000 \\
\hline$>2$ years & 2 & $1.19(0.81-1.57)$ & 0.000 & 0.0 & 0.854 \\
\hline \multicolumn{6}{|c|}{ Estimating method of mean and SD } \\
\hline Described & 3 & $1.07(0.49-1.65)$ & 0.000 & 90.4 & 0.000 \\
\hline Estimated & 6 & $1.23(0.70-1.79)$ & 0.000 & 93.0 & 0.000 \\
\hline
\end{tabular}

Notes: $\mathrm{N}$, number of studies; $P, P$-value for $\mathrm{SMD}=0 ; P, P$-value for heterogeneity test.

Abbreviations: AHF, acute HF; CHF, chronic HF; $95 \% \mathrm{Cl}, 95 \%$ confidence interval; CLIA, chemiluminescent immunoassay; HF, heart failure; ILMA, immunoluminometric assay; NOS, Newcastle-Ottawa Quality Assessment Scale; NYHA, New York Heart Association; SD, standard deviation; SMD, standardized mean difference.

independent prognostic biomarker for risk stratification in patients with HF.

Our results showed that higher circulating copeptin levels at baseline were significantly associated with the increased risk of all-cause death in patients with HF, with a pooled SMD (difference of mean copeptin level between death group and survival group/pooled SD) of 1.19. Overall, the risk of death from all causes in patients with HF increased 3\% for per unit $(1 \mathrm{pmol} / \mathrm{L})$ increase in baseline copeptin level and $>200 \%$ for 10 -fold copeptin increase. Meanwhile, compared to the group with lower copeptin level, the patients with HF with higher circulating copeptin levels were at a 1.69 times higher risk from all-cause death. Subgroup analyses also presented several important findings. In the subgroup analysis based on mortality and female percentage, the lower mortality group $(<30 \%)$ revealed a more prominent association as well as the higher female proportion group ( $\geq 30 \%$ ). Furthermore, when analyzing according to the sample size, a more extrusive association was found in studies with subjects $<200$ compared to studies with subjects $\geq 200$. As small studies with limited sample sizes were more likely to report larger beneficial effects, ${ }^{33}$ multicenter studies with large sample size were desired to evaluate a more accurate estimate about the association between copeptin and all-cause mortality in patients with HF.

Although some credible findings have been achieved, some limitations of our meta-analysis should be declared in this article. First, we restricted our study to all-cause mortality rather than HF related morbidity or mortality, which might show different relationship with copeptin. Second, we did not extract the original data from the eligible studies, which restricts further statistical estimate of circulating copeptin 
Meta-analysis estimates, given named study is omitted

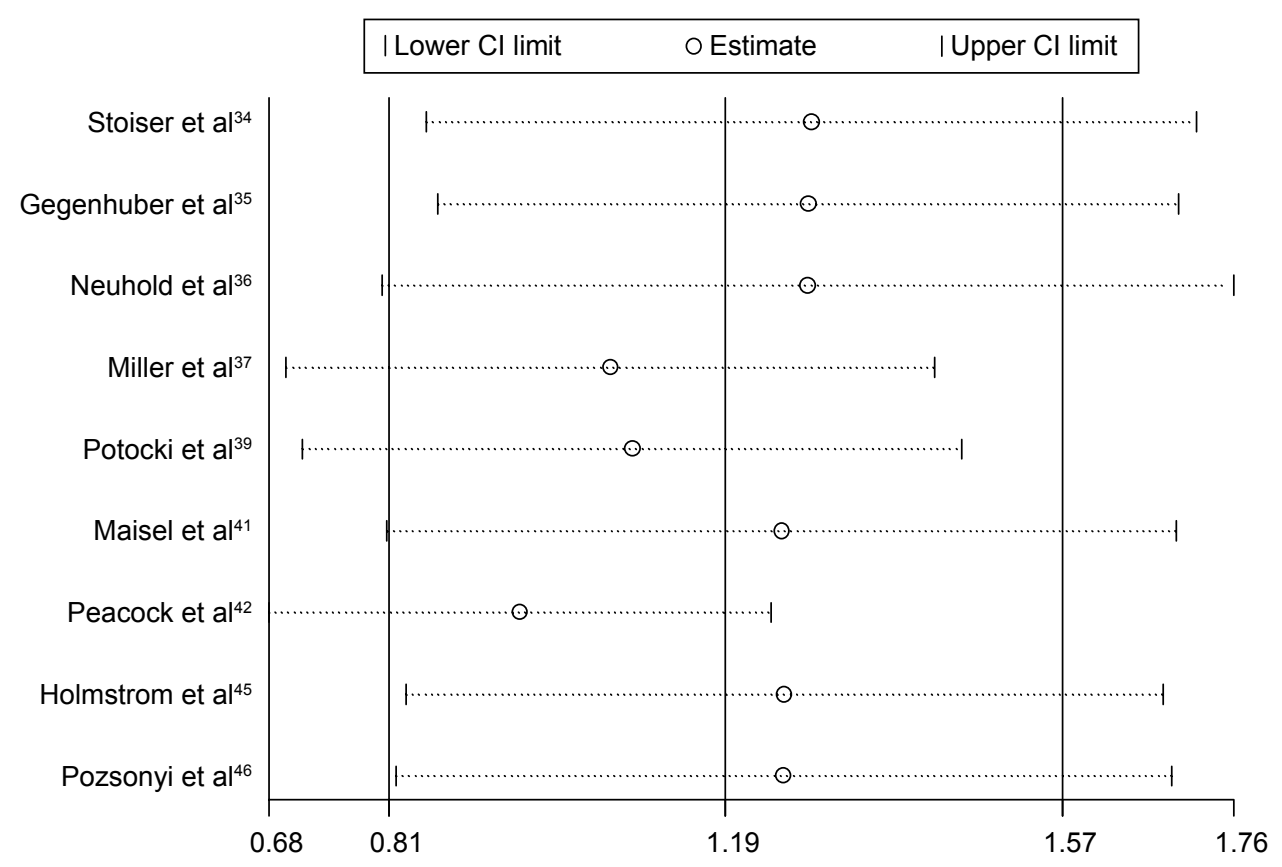

Figure 4 Sensitivity analysis of included studies (on SMD).

Abbreviations: $\mathrm{Cl}$, confidence interval; SMD, standardized mean difference.

levels in the evaluation of the prognostic accuracy in the receiver operating characteristic curve after HF. Third, merely crude RR (HR) could be achieved from some included studies. Therefore, the confounding factors of the different studies could not be adequately accounted for in the current analysis. Finally, publication bias might be a key element, for negative studies seemed to be more difficult to publish and have less impact; thus, the insufficiency of negative studies might influence the results of our meta-analyses. ${ }^{13}$

\section{Conclusion}

The results of our study indicated a prognostic role of copeptin that higher circulating copeptin levels were positively associated with the risk of all-cause mortality in patients with HF. Thus, in patients with HF, we recommended using copeptin as a new prognostic biomarker to provide better information not only in decision making for treatment but also in the prediction of clinical outcome. Since the exact mechanism of this association between copeptin and mortality in patients with HF is not fully understood, future welldesigned studies with large sample size are required.

\section{Acknowledgment}

The authors highly appreciate the support from all the participants.

\section{Disclosure}

The authors report no conflicts of interest in this work.

\section{References}

1. Mozaffarian D, Benjamin EJ, Go AS, et al. Heart Disease and Stroke Statistics-2016 Update: a Report From the American Heart Association. Circulation. 2016;133(4):e38-e60.

2. Chowdhury P, Kehl D, Choudhary R, Maisel A. The use of biomarkers in the patient with heart failure. Curr Cardiol Rep. 2013;15(6):372.

3. Balling L, Gustafsson F. Copeptin as a biomarker in heart failure. Biomark Med. 2014;8(6):841-854.

4. Holwerda DA. A glycopeptide from the posterior lobe of pig pituitaries. I. Isolation and characterization. Eur J Biochem. 1972;28(3):334-339.

5. Dunser MW, Wenzel V, Mayr AJ, Hasibeder WR. Management of vasodilatory shock: defining the role of arginine vasopressin. Drugs. 2003;63(3): 237-256.

6. Zhang R, Liu J, Zhang Y, Liu Q, Li T, Cheng L. Association between circulating copeptin level and mortality risk in patients with intracerebral hemorrhage: a systemic review and meta-analysis. Mol Neurobiol. Epub 2016 Jan 5.

7. Bolignano D, Cabassi A, Fiaccadori E, et al. Copeptin (CTproAVP), a new tool for understanding the role of vasopressin in pathophysiology. Clin Chem Lab Med. 2014;52(10):1447-1456.

8. Viasus D, Del Rio-Pertuz G, Simonetti AF, et al. Biomarkers for predicting short-term mortality in community-acquired pneumonia: a systematic review and meta-analysis. $J$ Infect. 2016;72(3):273-282.

9. Raskovalova T, Twerenbold R, Collinson PO, et al. Diagnostic accuracy of combined cardiac troponin and copeptin assessment for early rule-out of myocardial infarction: a systematic review and meta-analysis. Eur Heart J Acute Cardiovasc Care. 2014;3(1):18-27.

10. Theilade S, Rosenlund S, Hansen TW, Gotze J, Persson F, Rossing P. Increased copeptin in plasma predicts mortality and renal outcome in patients with type 1 diabetes. Diabetologia. 2015;58:S541-S542. 
11. Then C, Kowall B, Lechner A, et al. Plasma copeptin is associated with type 2 diabetes in men but not in women in the population-based KORA F4 study. Acta Diabetol. 2015;52(1):103-112.

12. Ramalho AA, Silva D, Cortez-Dias N, et al. Copeptin predicts long term prognosis in patients with worsening heart failure. Eur J Heart Fail. 2014; $16: 276$

13. Choi KS, Kim HJ, Chun HJ, et al. Prognostic role of copeptin after stroke: a systematic review and meta-analysis of observational studies. Sci Rep. 2015;5:11665.

14. De Marchis GM, Katan M, Weck A, et al. Copeptin and risk stratification in patients with ischemic stroke and transient ischemic attack: the CoRisk study. Int J Stroke. 2013;8(3):214-218.

15. Purroy F, Suarez I, Cambray S, Farre J, Sanahuja J, Benabdelhak I. Copeptin improves the prognostic models of early subsequent stroke after a transient ischemic attack. Int J Stroke. 2015;10:251.

16. Stroup DF, Berlin JA, Morton SC, et al. Meta-analysis of observational studies in epidemiology: a proposal for reporting. Meta-analysis of Observational Studies in Epidemiology (MOOSE) group. JAMA. 2000; 283(15):2008-2012.

17. Stang A. Critical evaluation of the Newcastle-Ottawa scale for the assessment of the quality of nonrandomized studies in meta-analyses. Eur J Epidemiol. 2010;25(9):603-605.

18. Higgins JP, Green S. Cochrane Handbook for Systematic Review of Interventions, Version 5.1.0. Copenhagen: The Nordic Cochrane Center 2011:2011.

19. Higgins JP, Thompson SG, Deeks JJ, Altman DG. Measuring inconsistency in meta-analyses. BMJ. 2003;327(7414):557-560.

20. DerSimonian R, Laird N. Meta-analysis in clinical trials. Control Clin Trials. 1986;7(3):177-188.

21. Morgenthaler NG, Struck J, Jochberger S, Dunser MW. Copeptin: clinical use of a new biomarker. Trends Endocrinol Metab. 2008;19(2): 43-49.

22. Serradeil-Le Gal C, Wagnon J, Valette G, et al. Nonpeptide vasopressin receptor antagonists: development of selective and orally active V1a V2 and V1b receptor ligands. Prog Brain Res. 2002;139:197-210.

23. Chatterjee $\mathrm{K}$. Neurohormonal activation in congestive heart failure and the role of vasopressin. Am J Cardiol. 2005;95(9A):8B-13B.

24. Baumann G, Dingman JF. Distribution, blood transport, and degradation of antidiuretic hormone in man. J Clin Invest. 1976;57(5): 1109-1116.

25. Robertson GL, Mahr EA, Athar S, Sinha T. Development and clinical application of a new method for the radioimmunoassay of arginine vasopressin in human plasma. J Clin Invest. 1973;52(9):2340-2352.

26. Jernberg T, Stridsberg M, Lindahl B. Usefulness of plasma N-terminal proatrial natriuretic peptide (proANP) as an early predictor of outcome in unstable angina pectoris or non-ST-elevation acute myocardial infarction. Am J Cardiol. 2002;89(1):64-66.

27. Nickel $\mathrm{CH}$, Bingisser R, Morgenthaler NG. The role of copeptin as a diagnostic and prognostic biomarker for risk stratification in the emergency department. BMC Med. 2012;10:7.

28. Voors AA, von Haehling S, Anker SD, et al. C-terminal provasopressin (copeptin) is a strong prognostic marker in patients with heart failure after an acute myocardial infarction: results from the OPTIMAAL study. Eur Heart J. 2009;30(10):1187-1194.

29. Masson S, Latini R, Carbonieri E, et al. The predictive value of stable precursor fragments of vasoactive peptides in patients with chronic heart failure: data from the GISSI-heart failure (GISSI-HF) trial. Eur $J$ Heart Fail. 2010;12(4):338-347.

30. Tentzeris I, Jarai R, Farhan S, et al. Complementary role of copeptin and high-sensitivity troponin in predicting outcome in patients with stable chronic heart failure. Eur J Heart Fail. 2011;13(7):726-733.
31. Miller WL, Grill DE, Struck J, Jaffe AS. Association of hyponatremia and elevated copeptin with death and need for transplantation in ambulatory patients with chronic heart failure. Am J Cardiol. 2013;111(6): 880-885.

32. Sun H, Sun T, Ma B, et al. Prediction of all-cause mortality with copeptin in cardio-cerebrovascular patients: a meta-analysis of prospective studies. Peptides. 2015;69:9-18.

33. Zhang Z, Xu X, Ni H. Small studies may overestimate the effect sizes in critical care meta-analyses: a meta-epidemiological study. Crit Care. 2013;17(1):R2.

34. Stoiser B, Mortl D, Hulsmann M, et al. Copeptin, a fragment of the vasopressin precursor, as a novel predictor of outcome in heart failure. Eur J Clin Invest. 2006;36(11):771-778.

35. Gegenhuber A, Struck J, Dieplinger B, et al. Comparative evaluation of B-type natriuretic peptide, mid-regional pro-A-type natriuretic peptide, mid-regional pro-adrenomedullin, and copeptin to predict 1-year mortality in patients with acute destabilized heart failure. J Card Fail. 2007;13(1):42-49.

36. Neuhold S, Huelsmann M, Strunk G, et al. Comparison of copeptin, B-type natriuretic peptide, and amino-terminal pro-B-type natriuretic peptide in patients with chronic heart failure: prediction of death at different stages of the disease. J Am Coll Cardiol. 2008;52(4):266-272.

37. Miller WL, Hartman KA, Hodge DO, et al. Response of novel biomarkers to BNP infusion in patients with decompensated heart failure: a multimarker paradigm. J Cardiovasc Transl Res. 2009;2(4):526-535.

38. Neuhold S, Huelsmann M, Strunk G, et al. Prognostic value of emerging neurohormones in chronic heart failure during optimization of heart failure-specific therapy. Clin Chem. 2010;56(1):121-126.

39. Potocki M, Breidthardt T, Mueller A, et al. Copeptin and risk stratification in patients with acute dyspnea. Crit Care. 2010;14(6):R213.

40. Alehagen U, Dahlstrom U, Rehfeld JF, Goetze JP. Association of copeptin and N-terminal proBNP concentrations with risk of cardiovascular death in older patients with symptoms of heart failure. JAMA. 2011;305(20):2088-2095.

41. Maisel A, Xue Y, Shah K, et al. Increased 90-day mortality in patients with acute heart failure with elevated copeptin secondary results from the biomarkers in acute heart failure (BACH) study. Circ Heart Fail. 2011;4(5):613-620.

42. Peacock WF, Nowak R, Christenson R, et al. Short-term mortality risk in emergency department acute heart failure. Acad Emerg Med. 2011;18(9):947-958.

43. Balling L, Kistorp C, Schou M, et al. Plasma copeptin levels and prediction of outcome in heart failure outpatients: relation to hyponatremia and loop diuretic doses. J Card Fail. 2012;18(5):351-358.

44. Bosselmann H, Egstrup M, Rossing K, et al. Prognostic significance of cardiovascular biomarkers and renal dysfunction in outpatients with systolic heart failure: a long term follow-up study. Int J Cardiol. 2013; 170(2):202-207.

45. Holmstrom A, Sigurjonsdottir R, Hammarsten O, Petzold M, Gustafsson D, Fu MLX. An integrated multiple marker modality is superior to NTproBNP alone in prognostic prediction in all-cause mortality in a prospective cohort of elderly heart failure patients. Eur Geriatr Med. 2013; 4(6):365-371.

46. Pozsonyi Z, Forhecz Z, Gombos T, Karadi I, Janoskuti L, Prohaszka Z. Copeptin (C-terminal pro arginine-vasopressin) is an independent longterm prognostic marker in heart failure with reduced ejection fraction. Heart Lung Circ. 2015;24(4):359-367.

47. Long-hai W, Qi-song C, Fang XIA, Chao F, Hai-jun HE, Ping Z. Prognostic value of copeptin, big endothelin-1 and N-terminal pro-brain natriuretic peptide in patients with chronic heart failure. Mod Lab Med. 2015;30(1):64-67, 71 
Therapeutics and Clinical Risk Management

Dovepress

\section{Publish your work in this journal}

Therapeutics and Clinical Risk Management is an international, peerreviewed journal of clinical therapeutics and risk management, focusing on concise rapid reporting of clinical studies in all therapeutic areas, outcomes, safety, and programs for the effective, safe, and sustained use of medicines. This journal is indexed on PubMed Central, CAS,

EMBase, Scopus and the Elsevier Bibliographic databases. The manuscript management system is completely online and includes a very quick and fair peer-review system, which is all easy to use. Visit http://www.dovepress.com/testimonials.php to read real quotes from published authors.

Submit your manuscript here: http://www.dovepress.com/therapeutics-and-clinical-risk-management-journal 